\section{AB0372 EXPLORING REFRACTORY DISEASE \& PERSISTENT SYMPTOMS IN RA/POLYJIA DESPITE BDMARDS: PATIENT \& PROFESSIONAL EXPERIENCES}

Hema Chaplin ${ }^{1}$, Ibone Verhey ${ }^{2}$, Nora $\mathrm{Ng}^{3}$, James Galloway ${ }^{4,5}$, Ian Scott ${ }^{6,7}$, Debajit Sen ${ }^{8,9}$, Rachel Tattersall ${ }^{10,11}$, Heidi Lempp ${ }^{4}$, Sam Norton ${ }^{1,4} .{ }^{1}$ King's College London, Health Psychology Section, London, United Kingdom; ${ }^{2}$ King's College London, London, United Kingdom; ${ }^{3}$ Guy's and St Thomas' NHS Foundation Trust, London, United Kingdom; ${ }^{4}$ King's College London, Inflammation Biology, London, United Kingdom; ${ }^{5}$ King's College Hospital NHS Foundation Trust, London, United Kingdom; ${ }^{6}$ Keele University, Stoke-on-Trent, United Kingdom; ${ }^{7}$ Midlands Partnership NHS Foundation Trust, Stoke-on-Trent, United Kingdom; ${ }^{8}$ University College London Hospitals NHS Foundation Trust, London, United Kingdom; ${ }^{9}$ University College London, Versus Arthritis Centre for Adolescent Rheumatology, London, United Kingdom; ${ }^{10}$ Sheffield Teaching Hospitals NHS Foundation Trust, Sheffield, United Kingdom; ${ }^{11}$ Barbara Ansell National Network for Adolescent and Young Adult Rheumatology, UK, United Kingdom

Background: Refractory disease is defined as not achieving a low disease activity target despite DMARDs. This definition does not account for patients with well controlled inflammation who experience persistent symptoms, or who have a high perceived disease impact. Furthermore, variations in professionals understanding of refractory disease and related concepts exists, with potential discordance when compared to patients understanding.

Objectives: To qualitatively explore patients and professionals understanding and experiences of refractory disease and persistent symptoms.

Methods: Semi-structured interviews were conducted with 13 RA and 3 Polyarticular JIA patients (on bDMARD not responding with DAS28>3.2) attending four UK Rheumatology clinics. Thirty-two healthcare professionals (working in Rheumatology >1year) were interviewed across 11 UK hospitals. Inductive thematic analysis was conducted, with descriptive statistics reported for quantitative data.

Results: Patients had not responded to on average 3 csDMARDs and 3.5 bDMARDs, with mean MSK-HQ=24.6, mean $\mathrm{DAS} 28=4.60$, and mean Patient Global=55.4. Healthcare professionals interviewed were predominantly adult trained (25/32), with mean 11.7 years' experience, comprising rheumatologists, nurses, physiotherapists, occupational therapists, psychologists, pharmacist, podiatrist, and social worker.

Key themes for both patients and professionals' experiences of refractory disease and persistent symptoms explored were: 1) Frustrations with the disease, non-response to medication and side effects, 2) Importance of areas not captured by the DAS28, 3) Patient-centred targets/care, 4) Role of other specialties, 5) Role of comorbidities, infections and/or joint damage, and 6) Patient acceptance, adjustment and resilience. Although patients expressed hopeful expectations despite poor experiences, this was in discordance to professionals' accounts of loss of trust/hope, disengagement and limited treatment options, with hope mainly for stratified medicines.

Patient specific emergent themes identified: 1) Disease not controlled fully but manageable, 2) Drugs do not work: at all versus over time, 3) Persistent pain, fatigue and restricted mobility are most problematic symptoms, 4) Life-limiting impact: practically, psychologically/emotionally and socially, and 5) Good support from rheumatology team but holistic approach needed.

Professionals grouped refractory disease into four key areas: 1) Refractory Inflammation vs Refractory Symptomology, 2) Biological processes, 3) Drug inefficacy/tolerability, and 4) Patient health beliefs/ behaviours.

Those with JIA had a greater variety in their experiences compared to those with RA. In addition to above themes they all highlighted the challenges of having a long-term illness so young, e.g. not knowing a life without pain or disease and lack of understanding in both themselves and others. Paediatric/Adolescent professionals noted differences in treating JIA compared to RA, e.g. joints affected and treatment guidelines/ availability not based on DAS equivalent scores.

Conclusion: These results highlight the potential need for a broader definition for refractory disease, and the need for holistic approaches to treatment that better support both patients, and professionals, in managing their condition.

Disclosure of Interests: Hema Chaplin: None declared, Ibone Verhey: None declared, Nora Ng: None declared, James Galloway Consultant for: Pfizer Inc, Ian Scott: None declared, Debajit Sen: None declared, Rachel Tattersall: None declared, Heidi Lempp: None declared, Sam Norton: None declared

DOI: 10.1136/annrheumdis-2019-eular.6809

\section{$\mathrm{AB} 0373$ \\ A COMPARATIVE EFFECTIVENESS STUDY OF ABATACEPT AND TNFI AGENTS IN PATIENTS WITH RHEUMATOID ARTHRITIS USING REAL-WORLD DATA}

Evo Alemao ${ }^{1}$, Sean Connolly ${ }^{1}$, Yedid Elbez ${ }^{2}$, Aarti Rao ${ }^{3}$, Yogesh Saini $^{3}$, Christine lannaccone ${ }^{4}$, Michael E. Weinblatt ${ }^{4}$, Nancy Shadick ${ }^{4} .{ }^{1}$ Bristol-Myers Squibb, Princeton, United States of America; ${ }^{2}$ Excelya, Boulogne-Billancourt, France; ${ }^{3} \mathrm{Mu}$ Sigma, Bangalore, India; ${ }^{4}$ Brigham and Women's Hospital, Boston, United States of America

Background: Introduction of multiple biologic DMARDs, targeted synthetic DMARDs and biosimilars has led to a paradigm shift in the management of patients (pts) with RA. There are, however, limited head-to-head studies comparing these agents to guide evidence-based treatment decisions. Abatacept versus adaliMumab comParison in bioLogic-naivE RA subjects with background MTX (AMPLE) was the first head-to-head randomised controlled trial to evaluate the efficacy of abatacept (ABA) and adalimumab. However, there are limited data replicating AMPLE findings in realworld settings.

Objectives: To compare effectiveness of ABA versus TNF inhibitors (TNFis) in pts with RA by line of therapy (LOT) and by LOT stratified by anti-citrullinated protein antibody (ACPA) status using data from real-world clinical practice.

Methods: Data from two independent RA registries comprising pts treated by physicians in routine care were used for the analysis. An RA disease-specific registry provided data on pts treated with TNFis; the other was a product-specific RA registry and provided data on pts treated with ABA. ${ }^{1,2}$ The disease-specific registry was a US-based single-centre registry; the product-specific registry was a multi-centre, 12-country registry excluding the US. Frequency matching on age (in years [yrs]; \pm 4 yrs window), RA disease duration (in yrs; \pm 4 yrs) and baseline CDAl category (remission [ $\leq 2.8]$, low activity [ $\leq 10]$, medium activity [ $\leq 22]$, high activity [>22]) between TNFi and ABA pts was done for biologic-naïve and experienced pts. Descriptive statistics were used to summarise baseline demographics, disease activity measures and serostatus for both treatment groups by LOT. Disease activity in the follow-up period was measured at the 12-month mark ( \pm 6 months). Change in disease activity after 12 months was evaluated for TNFi and ABA pts by LOT, and statistical comparison using Kruskal-Wallis test was performed. The analysis was repeated for pts stratified by ACPA status.

Table 1

Table 1. Baseline characteristics by LOT and ACPA status

\begin{tabular}{|c|c|c|c|c|c|c|c|c|}
\hline & \multirow{2}{*}{\multicolumn{4}{|c|}{ ACPA+ }} & \multicolumn{4}{|c|}{ ACPA- } \\
\hline & First-line & & & Subsequent-line & \multicolumn{2}{|c|}{ First-line } & \multicolumn{2}{|c|}{ Subsequent-line } \\
\hline & $\begin{array}{c}\text { ABA } \\
(n=68)\end{array}$ & $\begin{array}{l}\text { TNFis } \\
(\mathrm{n}=68)\end{array}$ & $\begin{array}{c}\text { ABA } \\
(n=60)\end{array}$ & $\begin{array}{l}\text { TNFis } \\
(n=60)\end{array}$ & $\begin{array}{c}\text { ABA } \\
(n=31)\end{array}$ & $\begin{array}{l}\text { TNFis } \\
(n=31)\end{array}$ & $\begin{array}{c}\text { ABA } \\
(n=21)\end{array}$ & $\begin{array}{l}\text { TNFis } \\
(n=21)\end{array}$ \\
\hline Age, years & $\begin{array}{l}54.9 \\
(12.9)\end{array}$ & $\begin{array}{l}57.0 \\
(13.3)\end{array}$ & $\begin{array}{l}55.7 \\
(10.3)\end{array}$ & $\begin{array}{l}58.2 \\
(10.4)\end{array}$ & $\begin{array}{l}54.3 \\
(8.5)\end{array}$ & $\begin{array}{l}56.4 \\
(9.5)\end{array}$ & $\begin{array}{c}52.0 \\
(12.4)\end{array}$ & $\begin{array}{l}54.8 \\
(12.3)\end{array}$ \\
\hline $\begin{array}{l}\text { RA duration, } \\
\text { years }\end{array}$ & $\begin{array}{l}9.9 \\
(9.3)\end{array}$ & $\begin{array}{l}11.0 \\
(9.4)\end{array}$ & $\begin{array}{c}17.0 \\
(10.7)\end{array}$ & $\begin{array}{c}17.9 \\
(10.1)\end{array}$ & $\begin{array}{c}4.1 \\
(4.6)\end{array}$ & $\begin{array}{c}4.4 \\
(4.2)\end{array}$ & $\begin{array}{l}9.2 \\
(9.6)\end{array}$ & $\begin{array}{l}10.3 \\
(8.9)\end{array}$ \\
\hline Female, $\mathbf{n}(\%)$ & $\begin{array}{c}52 \\
(76.5)\end{array}$ & $\begin{array}{c}55 \\
(80.9)\end{array}$ & $\begin{array}{c}45 \\
(75.0)\end{array}$ & $\begin{array}{c}54 \\
(90.0)^{*}\end{array}$ & $\begin{array}{c}21 \\
(67.7)\end{array}$ & $\begin{array}{c}26 \\
(83.9)\end{array}$ & $\begin{array}{c}18 \\
(85.7)\end{array}$ & $\begin{array}{c}19 \\
(90.5)\end{array}$ \\
\hline CDAl score & $\begin{array}{c}24.6 \\
(10.9)\end{array}$ & $\begin{array}{c}26.9 \\
(14.8)\end{array}$ & $\begin{array}{c}25.9 \\
(14.9)\end{array}$ & $\begin{array}{l}25.7 \\
(15.3)\end{array}$ & $\begin{array}{c}25.6 \\
(10.6)\end{array}$ & $\begin{array}{c}30.6 \\
(15.8)\end{array}$ & $\begin{array}{c}28.5 \\
(17.1)\end{array}$ & $\begin{array}{c}26.8 \\
(15.7)\end{array}$ \\
\hline
\end{tabular}

$A B A=$ abatacept; $A C P A=$ anti-citrullinated protein antibody; $L O T=$ line of therapy; $T N F i=T N F$ inhibitor

Table 2

Table 2. Change in disease activity (CDAI) by LOT and by LOT and ACPA status

\begin{tabular}{|c|c|c|c|c|c|}
\hline & & $\begin{array}{l}\text { Baseline CDAI } \\
\text { score }\end{array}$ & $\begin{array}{l}\text { Follow-up } \\
\text { CDAl score }\end{array}$ & $\begin{array}{c}\text { CDAI } \\
\text { reduction from } \\
\text { baseline, } \%\end{array}$ & $\begin{array}{l}\text { Absolute CDA } \\
\text { reduction from } \\
\text { baseline }\end{array}$ \\
\hline \multirow{2}{*}{ Biologic naïve } & $\begin{array}{c}\text { TNFis } \\
(\mathrm{n}=105)\end{array}$ & $28.4(16.1)$ & $13.3(13.8)$ & 53.3 & $15.1(15.7)$ \\
\hline & $\begin{array}{c}\mathrm{ABA} \\
(\mathrm{n}=105)\end{array}$ & $24.2(10.1)$ & $9.5(6.6)$ & 61.0 & $14.8(10.8)$ \\
\hline \multirow{2}{*}{$\begin{array}{l}\text { Biologic } \\
\text { experienced }\end{array}$} & $\begin{array}{c}\text { TNFis } \\
(n=91)\end{array}$ & $24.6(15.9)$ & $19.4(16.9)$ & 21.2 & $5.2(15.5)$ \\
\hline & $\begin{array}{c}\text { ABA } \\
(\mathrm{n}=91)\end{array}$ & $23.8(14.5)$ & $13.6(10.1)^{\star}$ & 43.0 & $10.2(13.4)^{*}$ \\
\hline \multirow{2}{*}{$\begin{array}{l}\text { ACPAt } \\
\text { biologic naïve }\end{array}$} & $\begin{array}{l}\text { TNFis } \\
(n=68)\end{array}$ & 26.9 (14.8) & $12.6(11.8)$ & 53.2 & $14.3(15.7)$ \\
\hline & $\begin{array}{c}\text { ABA } \\
(n=68)\end{array}$ & $24.6(10.9)$ & $8.2(6.0)$ & 66.6 & $16.4(10.8)$ \\
\hline \multirow{2}{*}{$\begin{array}{l}\text { ACPA+ } \\
\text { biologic } \\
\text { experienced }\end{array}$} & $\begin{array}{l}\text { TNFis } \\
(n=60)\end{array}$ & $25.7(15.3)$ & $19.6(16.6)$ & 24.0 & $6.2(13.7)$ \\
\hline & $\begin{array}{c}\text { ABA } \\
(n=60)\end{array}$ & $25.9(14.9)$ & $12.6(8.5)^{*}$ & 51.2 & $13.3(14.3)^{*}$ \\
\hline
\end{tabular}

Results: Data for 105 first-line and 91 second- or further-line (subsequent-line) matched pairs of TNFi and ABA pts were included in the analysis $(68$ first-line and 60 subsequent-line matched pairs of TNFi and ABA pts, respectively, in ACPA+ cohort; 31 first-line and 21 subsequent- 
line matched pairs of TNFi and ABA pts, respectively, in ACPA- cohort; Table 1). In the biologic-experienced pts, ABA (vs TNFi) had a higher reduction in CDAl score (10.2 vs 5.2, $\mathrm{p}=0.035$; Table 2). In the biologicexperienced ACPA+ pts, ABA (vs TNFi) had higher reduction in disease activity (CDAl: 13.3 vs 6.2, $\mathrm{p}=0.023$; Table 2; SDAl: 13.9 vs 7.0 $\mathrm{p}=0.046)$. No difference in disease activity was observed between the two groups among the ACPA- pts.

Conclusion: Real-world RA registry data further confirm findings from the AMPLE study that the overall efficacy of ABA is similar to TNFi agents in biologic-naïve pts with RA. Efficacy of ABA (vs TNFis) in biologicexperienced pts is greater, and greater reductions in joint disease activity in $A C P A+A B A$ (vs TNFis) pts were observed.

\section{REFERENCES}

[1] Brigham and Women's Hospital. BRASS. https://www.brassstudy.org/. Accessed September 12, 2018.

[2] Alten R, et al. RMD Open 2017;3:e000538.

Disclosure of Interests: Evo Alemao Shareholder of: Bristol-Myers Squibb, Employee of: Bristol-Myers Squibb, Sean Connolly Shareholder of: BristolMyers Squibb, Employee of: Bristol-Myers Squibb, Yedid Elbez Employee of: Employee of Excelya which received funding from Bristol-Myers Squibb as contract research organization., Aarti Rao Consultant for: Bristol-Myers Squibb, Yogesh Saini Consultant for: Bristol-Myers Squibb, Christine lannaccone: None declared, Michael E. Weinblatt Shareholder of: Stock option: CanFite, Lycera, Scipher, Inmedix, Grant/research support from: Crescendo Bioscience, Bristol Myers Squibb, Sanofi, Consultant for: AbbVie, Amgen, Bristol-Myers Squibb, CanFite, Corrona, Crescendo, GlaxoSmithKline, Gilead, Horizon, Lilly, Lycera, Merck, Novartis, Pfizer, Roche, Samsung, Scipher, Set Point, Nancy Shadick Grant/research support from: Bristol-Myers Squibb, Sanofi/Regeneron, Crescendo Biosciences, Mallinckrodt, Amgen, Consultant for: Consulting work for Bristol-Myers Squibb for under $\$ 10,000$.

DOI: 10.1136/annrheumdis-2019-eular.1447

\section{AB0374 ADALIMUMAB DISCONTINUATION IN PATIENTSWITH RHEUMATOID ARTHRITIS AFTER ACHIEVING SUSTAINED REMISSION}

Natalia Demidova ${ }^{1}$, Natalia Savushkina $^{2}$, Elena Galushko ${ }^{3}$, Andrey Gordeev ${ }^{3} .{ }^{1} V$. A.Nasonova Research Institute of Rheumatology, early arthritis, Moscow, Russian Federation; ${ }^{2} V$.A.Nasonova Research Institute of Rheumatology, early arthritis, Moscow, Russian Federation; ${ }^{2}$ V.A.Nasonova Research Institute of Rheumatology, early arthritis, Moscow, Russian Federation

Background: the most important factor in the progress of pharmacotherapy of RA was the widespread implementation of therapy with biological disease-modifying antirheumatic drugs (bDMARD). Recently, the issues of optimizing the management of patients have attracted more and more attention. First of all, we are talking about the possibility of reducing the dose and the abolition of bDMARD with the maintenance of remission ("biological-free remission").

Objectives: to assess whether adalimumab (AD) can be gradually discontinued during continuous methotrexate (MTX) use in patients with early rheumatoid arthritis (ERA).

Methods: Within the REMARCA (the Russian study of methotrexate and biological agents in early active arthritis) study, the investigators examined 20 patients (17 women and 3 men; median age, 51 [41.5; 56] years) with ERA (disease duration, $10[5.5 ; 20]$ months; DAS28, 5.17 [4.37; $6.51] ; 85 \%$ of the patients were seropositive for rheumatoid factor and $85 \%$ for anti-cyclic citrullinated peptide antibodies.

All the patients received subcutaneous MTX $25 \mathrm{mg} /$ week. Twelve weeks after beginning therapy with MTX, due to its inefficiency, ADA was added according to the standard scheme. Clinical and laboratory data was analyzed just before the therapy (point-3 months), then at the term of 6 $(n=20), 12(n=17), 24(n=17)$ and $36(n=17)$ months. To assess the effectiveness of therapy, indices of activity DAS28, CDAl and SDAl were used. The everyday life functioning of the patient was assessed quantitatively using the Russian version of the $\mathrm{HAQ}$ questionnaire.

Results: At week 24, with the combined therapy of methotrexate and adalimumab, about $75 \%$ of patients have reached remission/low disease activity: the median DAS28 was $3.0[1.65 ; 3.73] ; 85 \%$ of the patients achieved remission or low disease activity. After 3 months of ADA therapy, high or moderate disease activity remained in $3(15 \%)$ patients; median DAS28 was $4.4[4.3 ; 6.1]$; the drug was discontinued in them due to ineffective therapy. After 12-month follow-up, low DAS28 scores were observed in 5 $(29.4 \%)$, DAS28 remission was in $12(70.6 \%)$ of the 17 patients who continued ADA treatment; after 24 months, all the 17 patients were noted to have remission. After achieving sustained remission $(\geq 6$-month duration during $A D A$ therapy), there was a carefully controlled reduction (titration) in the dose of ADA with its complete discontinuation, by maintaining remission at 36-month follow-up; the median DAS28 was $1.6[1.4 ; 2.2]$.

The disease duration up to 1 year and functional class reduction to I in the first year of observation (or $=46,2 ; 95 \% \mathrm{Cl} 1,870-1141,178 ; \mathrm{P}=0.019$ and or $=44,2 ; 95 \% \mathrm{Cl} 1,795-1088,143 ; \mathrm{P}=0.02)$ were identified as predictors of maintaining long-term remission after the discontinuation of ADA RF positivity and the presence of erosion initially determined the impossibility of ADA withdrawal. (fig.1)

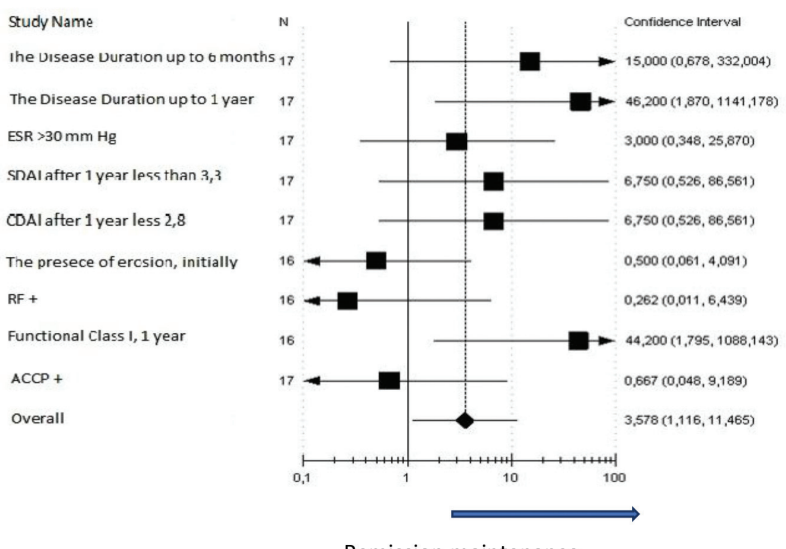

Remission maintenance

Figure 1. Influence of different factors on the possibility of withdrawal of ADA in patients with RA in remission.

Remission maintenance

Conclusion: In most patients with early rheumatoid arthritis, early induc tion of remission can be maintained after stopping the biologic therapy, under condition that the therapy was carried out by a combination of bDMARD and methotrexate. The maintenance of remission after discontinuation of ADA therapy was influenced by the duration of the disease and the depth of remission.

Disclosure of Interests: None declared

DOI: 10.1136/annrheumdis-2019-eular.4054

\section{AB0375 HYPOGAMMAGLOBULINEMIA AFTER RITUXIMAB TREATMENT IN PATIENTS WITH RHEUMATOID ARTHRITIS IS NOT RARE AND IS ASSOCIATED WITH BETTER RESPONSE}

Gerasimos Evangelatos ${ }^{1}$, George E. Fragoulis ${ }^{1}$, Kalliopi Klavdianou ${ }^{2}$, Dimitrios Vassilopoulos ${ }^{2}$, Alexios lliopoulos ${ }^{1}{ }^{1} 417$ Army Share Fund Hospital (NIMTS), Athens, Greece, Rheumatology Department, Athens, Greece; ' Joint Rheumatology Program, National and Kapodistrian University of Athens, School of Medicine-Clinical Immunology-Rheumatology Unit, 2nd Department of Medicine, Athens, Greece

Background: Rituximab (RTX) is used as a second line treatment in rheumatoid arthritis (RA), with well-established efficacy. One of the most common adverse events of RTX use is hypogammaglobulinemia (HGG). Objectives: To define, in RA patients treated with Rituximab, the frequency of $H G G$ (lgG $<700 \mathrm{mg} / \mathrm{dL}$ or $\mathrm{lgM}<40 \mathrm{mg} / \mathrm{dL}$ or $\mathrm{lg} A<70 \mathrm{mg} / \mathrm{dL}$ ) and to identify associations between its occurrence and clinical, epidemiological and other disease related features at baseline, RA outcomes and adverse events.

Methods: The patients received RTX for RA in two rheumatology centers from 1/2007 to 12/2018 were included. Demographical, clinical and laboratory parameters were recorded at baseline and at the last visit of the follow-up. Time of follow-up was defined as the time interval between the first RTX infusion and the last visit. Patients with monoclonal gammopathy and patients that received only one cycle of treatment were excluded. Severe infections were recorded defined as those which required hospitalization or antibiotics intravenously. Binomial regression analysis using stepwise backwards model having as dependent variables the "low IgG" or "low IgM" and independent variables: gender, age, 